\title{
Negative Pressure Wound Therapy-An Effective, Minimally Invasive Therapeutic Modality in Burn Wound Management
}

\author{
Endre Nagy ${ }^{1}$, István Juhász ${ }^{1,2}$ \\ ${ }^{1}$ Burn and Dermatosurgery Unit at Department of Dermatology, University of Debrecen Clinical Center, \\ Debrecen, Hungary \\ ${ }^{2}$ Coordinating Department of Surgical Specialties, Faculty of Dentistry, University of Debrecen, Debrecen, \\ Hungary \\ Email: ijuhi@yahoo.com
}

Received 9 March 2015; accepted 15 May 2015; published 18 May 2015

Copyright (C 2015 by authors and Scientific Research Publishing Inc.

This work is licensed under the Creative Commons Attribution International License (CC BY).

http://creativecommons.org/licenses/by/4.0/

(c) (1) Open Access

\begin{abstract}
Despite the advancement in burn therapy in the last decades the treatment of burn wounds still remains a challenging task. Infection is still a common complication; while sepsis remains the leading cause of death in severe burns. The research guided integration of new and effective techniques in burn wound management is mandatory. Negative pressure wound therapy (NPWT) is an effective and widely used technique in the management of problematic wounds. Previously existing indications include soft tissue traumas and chronic wounds such as diabetic, arterial, venous and pressure ulcers. The characteristics and challenges of these wounds have a lot in common with burns. Since the early 2000's there are experiences with the use of NPWT for the healing of second degree burn wounds. Our clinical experience shows that it is a minimally invasive and effective way of improving burn wound management. In this article we give a review of the literature showing the mechanisms, unmapped future opportunities, financial issues, and possible adverse effects of NPWT in burn therapy.
\end{abstract}

\section{Keywords}

NPWT, Negative Pressure Wound Therapy, VAC, Vacuum-Assisted Closure, Partial Thickness Burns

\section{Introduction}

Negative pressure wound therapy (NPWT) is a revolutionary technique of wound management which is often

How to cite this paper: Nagy, E. and Juhász, I. (2015) Negative Pressure Wound Therapy-An Effective, Minimally Invasive Therapeutic Modality in Burn Wound Management. International Journal of Clinical Medicine, 6, 301-306. 
used in cases where problematic wound healing is an issue. This system uses the power of a controlled vacuum equally distributed on the wound surface. Burn injury is not only a severe and common form of trauma worldwide, but the treatment of the burn wound is often a rather challenging task. In the USA alone approximately two million people are burned and 80,000 people are hospitalized while 6500 people die each year because of burns [1]. The research guided integration of new and effective techniques in burn wound management is mandatory.

\section{Evolution of NPWT}

The use of subatmospheric pressure for wound healing originates in the 1940's in the form of subatmospheric drainage of the subcutaneous tissue [2] [3]. The first report of the use of negative pressure for the closure of open wounds was released in 1987 using $-80 \mathrm{mmHg}$ negative pressure [4]. In 1989, 11 patients with post operational mediastinitis were treated with negative pressure for 24 days $(-700 \mathrm{mmHg})$ resulting in successful wound closure [5]. The expression: vacuum sealing was first mentioned in 1993 when 15 traumatic patients with open fractures and soft tissue injury were treated using polyurethane based dressings and negative pressure [6]. In 1996 further experience was published with traumatic patients [7]. In 1997 Morykwas and Argenta suggested the use of a foam dressing and negative pressure therapy for the treatment of chronic wounds, especially in elderly patients with weak potential for wound healing [8] [9]. They developed a porcine model and optimized the negative pressure level at $-125 \mathrm{mmHg}$ which soon became the most common setting. They also gave the name Vacuum-Assisted Closure (V.A.C. ${ }^{\circledR}$, a registered trademark of KCI). Today numerous companies and different NPWT solutions are available, including small single use mobile devices. All systems consist of a separate wound dressing (polyurethane foam, or moist gauze) which is laid on the open wound, an air-tight plastic film, suction tubes and a device that provides negative pressure. Suction fluid is collected in a plastic container (Figure 1). Some authors suggest that the use of intermittent therapy and lower negative pressure settings ( -75 or $-100 \mathrm{mmHg}$ ) would be beneficial instead of the routinely recommended continuous high pressure settings $(-125 \mathrm{mmHg})[10]$.

\section{Mechanism of NPWT}

The primary effect of NPWT in wound healing is complex (Table 1) [11]. Due to vacuum there is a macroscopic shrinkage of the wound (macrodeformation) [12]. The wound surface also undergoes microdeformation at the interface with the foam dressing. This is a type of micro mechanical effect that changes the cell function. Chronic wounds with excess fluid buildup, decreased circulation and tissue hypoxia are often accompanied with bacterial colonization which prohibits wound healing. These problems also occur in partial thickness (or second degree) burn wounds. NPWT removes fluid, toxins, bacteria, tissue-degrading enzymes and stimulates micro-

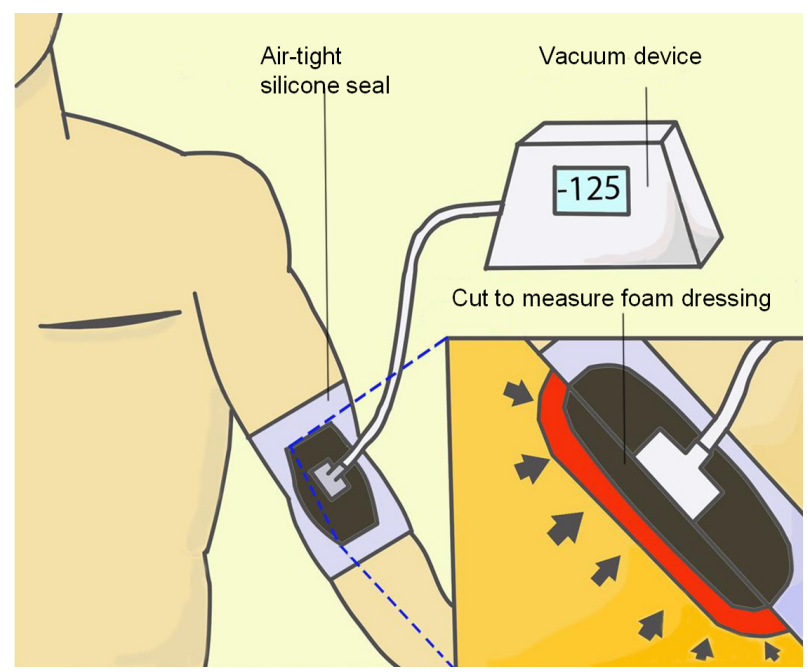

Figure 1. Schematic illustration of the components of a NPWT system. 
Table 1. Effect of NPWT on wound healing.

\begin{tabular}{cc}
\hline Primary mechanism & Secondary mechanism \\
\hline Macrodeformation & Cellular response \\
Microdeformation & Inflammation \\
Fluid removal & Granulation tissue formation \\
Wound environment alteration & Peripheral nerve response \\
& Enhanced microcirculation \\
& Reduction of stasis zone \\
\hline
\end{tabular}

circulation, while altering the wound environment creating a moist and warm environment optimal for wound healing [13] [14]. Gene expression profiling of samples taken from a wound treated with negative pressure shows that there is a significant change in the regulation of gene expression. Genes promoting proliferation and inflammation were found over expressed, while genes that take part in cell differentiation were under expressed [15].

\section{Indication, Contraindication and Possible Adverse Effects}

NPWT is commonly used in numerous indications such as traumatic wounds, chronic ulcers (arterial, venous, diabetic, pressure), burns and partial thickness skin grafting. In some cases there are RCT-s that prove NPWT to be more effective than conventional therapy [16]-[18]. NPWT can be used to help the total closure of the wound, or to prepare the wound before skin grafting, or using a scaffold or flap [19]. The use of NPWT is contraindicated if there is remaining necrosis, malignant tissue, osteomyelitis, or untreated fistula in the wound area. Caution should be taken when using close to blood vessels because it can cause bleeding, and also in close proximity to visceral organs because of the risk of fistula formation [20]. Using NPWT is not contraindicated with patients who suffer from coagulophathy, but strict monitoring is recommended. The use of uncontrolled central vacuum systems harbors the most serious risk of adverse reactions [21].

\section{NPWT in Burn Therapy}

Despite the advancement in burn therapy in the last decades the treatment of burn wounds still remains a challenging task, no wonder the use of NPWT became popular in burn units [22]. Infection is still a common complication; while sepsis remains the leading cause of death in severe burns [23]. The acute burn wound is a dynamic state that consists of three tissue zones: the zone of necrosis, the zone of stasis and the zone of hyperemia [24] (Figure 2). The key of this dynamic state is that in the early phase the zone of stasis can be transformed into viable tissue with adequate treatment (by restoring the circulation), or can easily become necrotic if the conditions are not optimal (burn wound conversion). Partial thickness burns are always accompanied by excess fluid buildup, and microcirculation disorder, which offers ideal conditions for microbial colonization. The use of NPWT in burn wounds is believed to be beneficial especially because the removing of excess fluid containing toxic mediators and bacteria, reduction of oedema and increasing tissue perfusion which helps the wound healing and stops the extension of necrosis. In 2003 the US Food and Drug Administration have approved the use of NPWT systems in the therapy of partial thickness burns. In 2004 a retrospective analysis was made including 60 burned children treated with NPWT for autologous partial thickness skin grafting resulting in increased mobility and compliance compared to conventional therapy [25]. In the same year a study was released examining patients with both sided hand burns. In case of each patient one hand was treated with conventional silver-sulfadiazine while the other was treated with NPWT. The study proved that when using NPWT the progression of burns was significantly less compared to conventional therapy [26]. Because dressing changes can be rather painful an application of a non-adherent wound dressing on the burn wound surface combined with NPWT can be useful [27]. In 2009 a pediatric burn case was reported with close proximity to the anus which was treated with NPWT allowing 100\% graft adhesion and no bacterial contamination [28]. The enhanced total body wrap is a novel technique which was introduced in 2013. By using 3 - 4 NPWT devices, long thin foam dressing stripes and covering the whole body in air-tight plastic film this technique was proven to be effective in partial thickness burns with a high percentage of total body surface area (TBSA) [29]. Topical antiseptics such as silver 
based dressings are ubiquitously used in burn treatment. One novel approach to NPWT in burns is to modify the foam dressing with silver taking advantage of its antimicrobial effect [30]. Another idea to augment NPWT is to instill normal saline or even antimicrobial solutions through one of the NPWT system's tubes to support wound healing [31]. In a 2014 study NPWT decreased mortality in a murine model of burn wound sepsis involving Pseudomonas aeruginosa infection [32]. Unfortunately, recent studies show, that there is a lack of evidence proving the statistically significant benefits of NPWT in burn therapy compared to conventional therapy [33] [34]. The difficulty of correct data analysis might reside in low case numbers and that the field is so special that it makes it hard to compare cases. Our clinical experience shows that NPWT is an effective, minimal invasive therapeutic modality in burn wound healing, especially in severe cases where otherwise our chance of success would be minimal (Figure 3).

\section{Financial Issues}

Although the instrumentation of NPWT is expensive compared to conventional wound treatment, it is widely used in developed countries. The explanation is that the main indication field of NPWT is wounds with problematic healing such as chronic wounds or burns. It is believed that the overall cost of conventional therapy of these wounds would be higher or the same due to the use of different kinds and high quantities of expensive wound dressings and increased hospitalization time [35] [36]. Unfortunately no random controlled clinical trial is available that compares the costs in case of burn wounds.

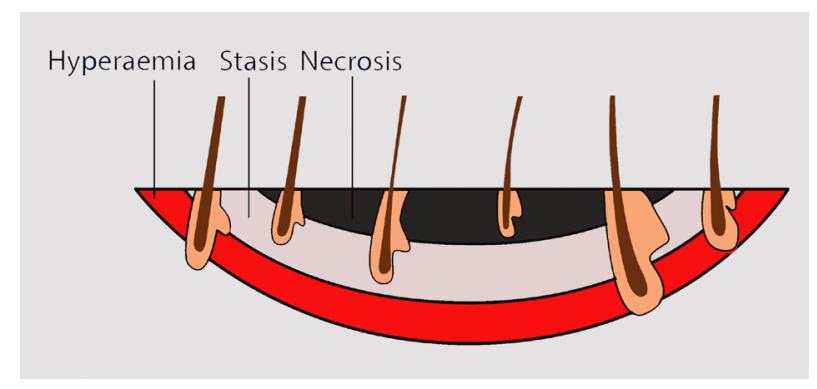

Figure 2. The zones of an acute burn wound. (Based on Ref. [24])

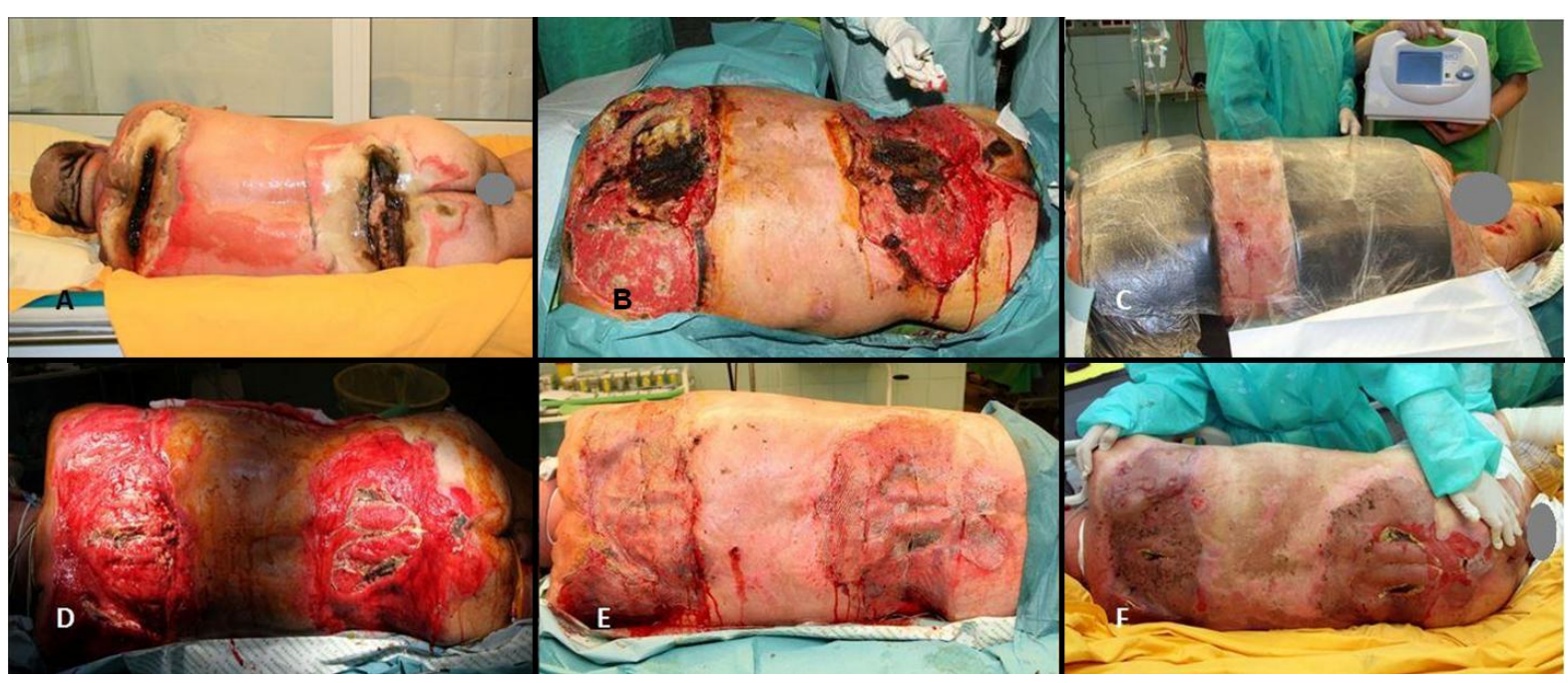

Figure 3. Case study: A 60 years old patient was injured in a high-voltage accident and suffered electrical shock with severe deep burns (Third degree, 35\% TBSA). A: Primary state: deep necrosis on the skin of the back. B: The wound after the surgical necrectomy. C: Patient during NPWT therapy. D: The cleared wound site due to NPWT therapy. E: We performed autologous partial thickness skin grafting followed by additional NPWT therapy resulting in graft adhesion. F: The acquired total wound closure three months after the accident. (With permission of Promenade Medical Publishing Co, Budapest, Hungary) 


\section{Conclusion}

NPWT is an effective and widely used technique in the management of problematic wounds. Since the early 2000's there are experiences with the use of NPWT for the healing of second degree burn wounds. Our clinical experience shows that it is a minimally invasive and effective way of improving burn wound management. Previously existing indications include soft tissue traumas and chronic wounds such as diabetic, arterial, venous and pressure ulcers. The characteristics and challenges of these wounds have a lot in common with burns. Studies have been done proving the effectiveness of NPWT in second degree burn wounds, but more RCT-s with higher patient numbers are needed for further knowledge in the topic. Exciting and untapped opportunities still remain in this technique e.g. the use of antimicrobial silver, or instillation combined with NPWT. The risk of adverse effects using NPWT can be minimized when using correct systems in correct indications. Cost may be an important issue but taken the unique gap stopping qualities of the technique into consideration, it may not be as crucial as believed.

\section{References}

[1] Brigham, P.A. and McLoughlin, E. (1996) Burn Incidence and Medical Care Used in the Unites States: Estimates, Trends, and Data Sources. Journal of Burn Care Rehabilitation, 17, 95-107. http://dx.doi.org/10.1097/00004630-199603000-00003

[2] Fay, M.F. (1987) Drainage Systems. Their Role in Wound Healing. AORN Journal, 46, 442-443, 445, 447, 449-452, 454-456. http://dx.doi.org/10.1016/S0001-2092(07)66456-4

[3] Fox 4th, J.W. and Golden, G.T. (1976) The Use of Drains in Subcutaneous Surgical Procedures. American Journal of Surgery, 132, 673-674. http://dx.doi.org/10.1016/0002-9610(76)90372-X

[4] Iusupov, Iu.N. and Epifanov, M.V. (1987) Active Drainage of Wound. Vestnik Khirurgii Imeni I. I. Grekova, 138, 42-46.

[5] Durandy, Y., Batisse, A., Bourel, P., Dibie, A., Lemoine, G. and Lecompte, Y. (1989) Mediastinal Infection after Cardiac Operation. A Simple Closed Technique. Journal of Thoracic and Cardiovascular Surgery, 97, 282-285.

[6] Fleischmann, W., Strecker, W., Bombelli, M. and Kinzl, L. (1993) Vacuum Sealing as Treatment of Soft Tissue Damage in Open Fractures. Der Unfallchirurg, 96, 488-492.

[7] Voinchet, V. and Maggalon, G. (1996) Vacuum Assisted Closure. Wound Healing by Negative Pressure. Annales de Chirurgie Plastique et Esthétique, 41, 583-589.

[8] Argenta, L.C. and Morykwas, M.J. (1997) Vacuum Assisted Closure: A New Method for Wound Control and Treatment: Clinical Experience. Annals of Plastic Surgery, 38, 563-576. http://dx.doi.org/10.1097/00000637-199706000-00002

[9] Morykwas, M.J., Argenta, L.C., Shelton-Brown, E.I. and McGuirt, W. (1997) Vacuum Assisted Closure: A New Method for Wound Control and Treatment: Animal Studies and Basic Foundation. Annals of Plastic Surgery, 38, 553-562. http://dx.doi.org/10.1097/00000637-199706000-00001

[10] Ahearn, C. (2009) Intermittent Negative Pressure Wound Therapy and Lower Negative Pressures-Exploring the Disparity between Science and Current Practice: A Review. Ostomy Wound Management, 55, 22-28.

[11] Huang, C., Leavitt, T., Bayer, L.R. and Orgill, D.P. (2014) Effect of Negative Pressure Wound Therapy on Wound Healing. Current Problems in Surgery, 51, 301-331. http://dx.doi.org/10.1067/j.cpsurg.2014.04.001

[12] Orgill, D.P., Manders, E.K., Sumpio, B.E., Lee, R.C., Attinger, C.E., Gurtner, G.C., et al. (2009) The Mechanisms of Action of Vacuum Assisted Closure: More to Learn. Surgery, 146, 40-51. http://dx.doi.org/10.1016/j.surg.2009.02.002

[13] Lancerotto, L., Bayer, L.R. and Orgill, D.P. (2012) Mechanisms of Action of Microdeformational Wound Therapy. Seminars in Cell \& Developmental Biology, 23, 987-992. http://dx.doi.org/10.1016/j.semcdb.2012.09.009

[14] Winter, G.D. and Scales, J.T. (1963) Effect of Air Drying and Dressings on the Surface of a Wound. Nature, 197, 91-92. http://dx.doi.org/10.1038/197091b0

[15] Nuutila, K., Siltanen, A., Peura, M. Harjula, A., Nieminen, T., Vuola, J., et al. (2013) Gene Expression Profiling of Negative-Pressure-Treated Skin Graft Donor Site Wounds. Burns, 39, 687-693. http://dx.doi.org/10.1016/j.burns.2012.09.014

[16] Joseph, E., Hamori, C.A., Bergman, S., Roaf, E., Swann, N.F. and Anastasi, G.W. (2000) A Prospective, Randomized Trial of Vacuum-Assisted Closure versus Standard Therapy of Chronic Nonhealing Wounds. Wounds, 12, 60-67.

[17] Ulusal, A.E., Sakin, M.S., Ulusal, B., Cakmak, G. and Tuncay, C. (2011) Negative Pressure Wound Therapy in Patients with Diabetic Foot. Acta Orthopaedica et Traumatologica Turcica, 45, 254-260.

http://dx.doi.org/10.3944/AOTT.2011.2283 
[18] Yao, M., Fabbi, M., Hayashi, H., Park, N., Attala, K., Gu, G., et al. (2014) A Retrospective Cohort Study Evaluating Efficacy in High-Risk Patients with Chronic Lower Extremity Ulcers Treated with Negative Pressure Wound Therapy. International Wound Journal, 11, 483-488. http://dx.doi.org/10.1111/j.1742-481X.2012.01113.x

[19] Kang, G.C., Por, Y.C. and Tan, B.K. (2010) In Vivo Tissue Engineering over Wounds with Exposed Bone and Tendon: Autologous Dermal Grafting and Vacuum-Assisted Closure. Annals of Plastic Surgery, 65, 70-73. http://dx.doi.org/10.1097/SAP.0b013e3181a72f77

[20] FDA Safety Communication (2011) UPDATE on Serious Complications Associated with Negative Pressure Wound Therapy Systems: FDA Safety Communication. http://www.fda.gov/MedicalDevices/Safety/AlertsandNotices/ucm244211.htm

[21] Ren, H. and Li, Y. (2014) Severe Complications after Negative Pressure Wound Therapy in Burned Wounds: Two Case Reports. Therapeutics and Clinical Risk Management, 2014, 513-516. http://dx.doi.org/10.2147/TCRM.S66117

[22] Monafo, W.W. (1992) Then and Now: 50 Years of Burn Treatment. Burns, 18, S7-S10. http://dx.doi.org/10.1016/0305-4179(92)90062-Y

[23] Sharma, B.R., Harish, D., Singh, V.P. and Bangar, S. (2006) Septicemia as a Cause of Death in Burns: An Autopsy Study. Burns, 32, 545-549. http://dx.doi.org/10.1016/j.burns.2006.02.008

[24] Zawacki, B. (1974) Reversal of Capillary Stasis and Prevention of Necrosis in Burns. Annals of Surgery, 180, 98-102. http://dx.doi.org/10.1097/00000658-197407000-00015

[25] Hoeller, M., Schintler, M.V., Pfurtscheller, K., Kamolz, L.P., Tripolt, N. and Trop, M. (2014) A Retrospective Analysis of Securing Autologous Split-Thickness Skin Grafts with Negative Pressure Wound Therapy in Pediatric Burn Patients. Burns, 40, 1116-1120. http://dx.doi.org/10.1016/j.burns.2013.12.007

[26] Kamolz, L.P., Andel, H., Haslik, W., Winter, W., Meissl, G. and Frey, M. (2004) Use of Subatmospheric Pressure Therapy to Prevent Burn Wound Progression in Human: First Experiences. Burns, 30, 253-258. http://dx.doi.org/10.1016/j.burns.2003.12.003

[27] Terrazas, S.G. (2006) Adjuvant Dressing for Negative Pressure Wound Therapy in Burns. Ostomy Wound Management, 52, 16-18.

[28] Psoinos, C.M., Ignotz, R.A., Lalikos, J.A., Fudem, G., Savoie, P. and Dunn, R.M. (2009) Use of Gauze-Based Negative Pressure Wound Therapy in a Pediatric Burn Patient. Journal of Pediatric Surgery, 44, e23-e26. http://dx.doi.org/10.1016/j.jpedsurg.2009.09.022

[29] Low, O.W., Chong, S.J. and Tan, B.K. (2013) The Enhanced Total Body Wrap-The New Frontier in Dressing Care for Burns. Burns, 39, 1420-1422. http://dx.doi.org/10.1016/j.burns.2013.03.010

[30] Stinner, D.J., Waterman, S.M., Masini, B.D. and Wenke, J.C. (2011) Silver Dressings Augment the Ability of Negative Pressure Wound Therapy to Reduce Bacteria in a Contaminated Open Fracture Model. The Journal of Trauma, 71, S147-S150. http://dx.doi.org/10.1097/TA.0b013e318221944a

[31] Kim, P.J., Attinger, C.E., Steinberg, J.S., Evans, K.K., Lehner, B. and Willy, C. (2013) Negative Pressure Wound Therapy with Instillation: International Consensus Guidelines. Plastic and Reconstructive Surgery, 132, 1569-1579.

[32] Liu, Y., Zhou, Q., Wang, Y., Liu, Z., Dong, M., Wang, Y., et al. (2014) Negative Pressure Wound Therapy Decreases Mortality in a Murine Model of Burn-Wound Sepsis Involving Pseudomonas Aeruginosa Infection. PLoS ONE, 9, e90494. http://dx.doi.org/10.1371/journal.pone.0090494

[33] Dumville, J.C. and Munson, C. (2012) Negative Pressure Wound Therapy for Partial-Thickness Burns. The Cochrane Database of Systematic Reviews. http://onlinelibrary.wiley.com/doi/10.1002/14651858.CD006215.pub3/pdf

[34] Molnar, J.A., Heimbach, D.M., Tredget, E.E., Hickerson, W.L., Still, J.M., Luterman, A., et al. (2004) Prospective Randomized Controlled Multicenter Trial Applying Subatmospheric Pressure to Acute Hand Burns: An Interim Report. 2nd World Union of Wound Healing Societies' Meeting, Paris, 18-23 July 2004.

[35] Braakenburg, A., Obdeijn, M.C., Feitz, R., van Rooij, I.A., van Griethuysen, A.J. and Klinkenbijl, J.H. (2006) The Clinical Efficacy and Cost Effectiveness of the Vacuum-Assisted Closure Technique in the Management of Acute and Chronic Wounds: A Randomized Controlled Trial. Plastic and Reconstructive Surgery, 118, 390-397. http://dx.doi.org/10.1097/01.prs.0000227675.63744.af

[36] Vuerstaek, J.D., Vainas, T., Wuite, J., Nelemans, P., Neumann, M.H. and Veraart, J.C. (2006) State-of-the-Art Treatment of Chronic Leg Ulcers: A Randomized Controlled Trial Comparing Vacuum-Associated Closure (V.A.C.) with Modern Wound Dressings. Journal of Vascular Surgery, 44, 1029-1037. http://dx.doi.org/10.1016/j.jvs.2006.07.030 